\title{
Intersections of two isiZulu genderlects and the construction of skesana identities
}

Thabo Msibi and Stephanie Rudwick

University of KwaZulu-Natal

E-mail: msibi@ukzn.ac.za and rudwicks@ukzn.ac.za

\begin{abstract}
Drawing on Youdell's $(2000,2005,2006)$ work on identity formation, we examine in this article multiple performances of gender identities in relation to a particular language use among African men who engage in same-sex relations. Based on semi-ethnographic research and in-depth interviews with African men who are isiNgqumo speakers in the Durban metropolitan area in KwaZulu-Natal, this article portrays the intersectional nature of two genderlects. The isiNgqumo lexicon is characterised largely by what Zulu speakers refer to as "deep" lexicon, and a closer examination reveals that a substantial number of lexical items are drawn from the isiHlonipho variety of Zulu, also termed "isiHlonipho Sabafazi" ('women's language of respect'). Hlonipha (lit. 'respect') social actions and language use are representative of showing submissiveness towards males and other people who are considered superiors. On the basis of the experiences of men who engage in samesex relations and who self-identify as skesana, we argue that an isiNgqumo variety that draws from the isiHlonipho lexicon represents a linguistic variety that is linked to a heteronormative and patriarchal cultural system which renders femininity an inferior subject position. Within this gendered order, certain linguistic expressions of isiNgqumo can create tension-riddled identity categories and allow for complex positioning for skesanas, many of whom draw on heteronormative and heteropoleric categories in the construction of their sexual and gender identities.
\end{abstract}

Keywords: IsiNgqumo, hlonipha, language, Zulu, identity

\section{Introduction}

This article is based on a sociolinguistic analysis of the isiNgqumo lexicon, a linguistic variety in South Africa spoken predominately by African men who engage in same-sex relations, many of whom are Zulu mother tongue speakers. Two questions were central to this study, namely (i) What are the characteristic lexical features of isiNgqumo?, and (ii) What are the relationships between the linguistic characteristics of isiNgqumo, expressions of same-sex desire, and the gender and ethnic identities of its speakers? Based on ethnographic research and the analysis of in-depth interviews with isiNgqumo speakers in the Durban metropolitan area of KwaZulu-Natal, this article offers some answers to these questions, and reveals that isiNgqumo is connected to isiHlonipho, another African linguistic variety which, in certain contexts, can be considered a genderlect like isiNgqumo. 
The isiNgqumo lexicon is largely characterised by what Zulu speakers refer to as "deep" lexicon, i.e. a lexicon drawing on some archaic linguistic forms rarely utilised in today's communities of linguistic practice, and a closer examination reveals that a substantial number of lexical items are drawn from the isiHlonipho variety of Zulu, also termed "isiHlonipho Sabafazi" ('women's language of respect'). This linguistic variety can be described as a politeness register primarily, but not exclusively, employed by Zulu females in traditional rural KwaZulu-Natal areas before and after marriage. Hlonipha social actions and language use are representative of showing referential submissiveness towards males and other persons who are considered superior in sociocultural hierarchy.

We argue in this article that the isiNgqumo variety we are examining draws to some extent from the isiHlonipho lexicon, which renders the former a linguistic means that is deeply gendered and linked to a patriarchal cultural system constructing femininity as an inferior subject position. Within this gendered order, some linguistic expressions of isiNgqumo create tension-riddled identity categories, and allow for complex positioning of African men who engage in same-sex relations, many of whom draw on heteronormative and heteropoleric categories in the construction of their sexual and gender identities. We further argue that it is deeply ironic that African men who engage in same-sex relations, who are widely discriminated against in South Africa, may contribute to the perpetuation of the matrix of gender oppression through their own linguistic and social behaviour. However, this does not discount the emancipatory and agentic possibilities that the use of isiNgqumo may offer these men (for many "gay" men, isiNgqumo offers a sense of community and an opportunity to escape public homophobia through engaging in a "secret" and "foreign" language with friends - see Msibi 2013 and Rudwick and Ntuli 2008); rather, our position locates the argument within a broader, outwardly patriarchal, national context.

The article focuses on a group of men who engage in same-sex relations, known as skesanas. A skesana identity is constructed on the basis of femininity. Skesanas have been defined as young men who "[like] to be fucked" (McLean and Ngcobo 1995: 164). In other words, a skesana is a man who desires the kind of sex with a man where he engages in the "passive" role only without ever taking over the penetrative act. The African men who call themselves skesanas are, by and large, feminine and effeminate and tend to be quite visibly "out" in South Africa. Skesanas have further been described as desiring "masculine men" who could be considered "accidental" homosexuals because they have sex with men whom they believe to be intersex or someone who pretends to be "female" (McLean and Ngcobo 1995: 166). Some skesanas see themselves as women (Reddy and Louw 2002, Ntuli 2009, Rudwick 2011, Msibi 2013) and others as "gay" men (McLean and Ngcobo 1995).

It is important to stress at this early stage, in relation to hlonipha, that our point in this article is not to suggest that hlonipha use is a static, non-evolving cultural positioning. It is also not our aim to highlight how hlonipha behavioural practices alienate "gay" skesana identities, nor is it to show how isiHlonipho linguistic expressions predetermine an inferior subject position for "gay" men. Rather, we seek to show how both isiHlonipho lexicons and hlonipha cultural practices cohere with isiNgqumo both lexically and practically. In essence, we suggest that both linguistic forms share lexical similarities as isiNgqumo draws mainly on the isiHlonipho lexicons. However, we do not seek to suggest that this etymological connection results in similar cultural practices. We hold that it is due to inherited patriarchal cultures that use of these linguistic varieties results in the marginalisation of femininity. 
Cognisant of the contested panoptic use of Western sexual identity labels in African contexts, we use the rather lengthy concept of 'men who engage in same-sex relations' when referring to our participants. Western sexual categories are increasingly being questioned in African contexts given the failure of these categories to capture the varied ways in which same-sex engagement is understood and performed in these contexts. Recently, for instance, Sigamoney and Epprecht (2013) have shown, through a comprehensive study of more than 1000 South African township youths, how concepts like 'homosexuality' and other Western categories of identification fail to resonate with the local people as many do not know the terms and concepts or do not understand their meanings. In fact, the authors found that the sheer majority of township youths and police officers in their study did not use the word "homosexual", with less than $5 \%$ of their participants using it to refer to men and women who have same-sex attractions.

While the same study also revealed that "gay" and "lesbian" were often the terms preferred by study participants, we are also guarded in using these terms as they often take on particular localised meanings which differ drastically from the Western conventional meaning (see Msibi 2013). Additionally, Queer Theory has highlighted the fluid nature of identification, thereby troubling the assumed static nature of labels such as "gay" and "lesbian". We are, however, also constrained to label the participants as "queer" as this concept is not at all used in contexts like South Africa. The general concept of 'men who engage in same-sex relations' therefore assists not only in avoiding an imposition of terminology and concepts, but also in highlighting the complexities of sexual identification with specific reference to South Africa.

We begin our argument by providing a discussion on the two linguistic varieties which concern this study (sections 2 and 3 ). This is followed by a discussion on the conceptual, theoretical and methodological positions adopted in this article (section 4). By exploring the genealogy of the skesana identity as a subject position constructed by African men who engage in same-sex relations through three narratives presented in this article, we showcase the ways in which the heteronormative, gendered positioning of this identity may have been historically informed by sexual politics of the mines, where same-sex sexual engagements and commitments among men are primarily defined along very traditional, heteronormative gender lines.

\section{IsiNgqumo}

Only a few years have passed since isiNgqumo first attracted attention among South African sociolinguists and gender scholars. Thus far, no comprehensive study or dictionary of the variety has been published, although we have met a number of isiNgqumo-speaking individuals who intend to compose such a volume. We provide a short list of lexical items in the appendix of this article to demonstrate that the isiNgqumo lexicon transcends a mere sexual register by the incorporation of many non-sexual lexical items. Grammatically, isiNgqumo is based on the Nguni languages. The variety can be considered a genderlect (see theoretical framework below) as by speaking it "people do gender linguistically" (Motschenbacher 2007: 263), but also because it is mainly "gay" men with access to specific communities of practice (see Msibi 2013) who employ it. IsiNgqumo's distinctive feature is not its grammar but its lexicon, as is the case with most genderlects. According to Rudwick and Ntuli (2008), isiNgqumo words belong to the lexical categories of nouns, adjectives and verbs, with no distinct prepositions, adverbs or pronouns. As has been noted before in the context of "gay speech varieties" (Baker 2002, Cage 2003, Rudwick and Ntuli 
2008), overlexification is taking place where semantic frames of the lexical items mostly revolve around sex discourse. However, as already mentioned, the semantic frame of the isiNgqumo lexicon reaches far beyond a mere sexual register, as can be seen in the appendix.

As regards the etymology of isiNgqumo, researchers have not been of one voice. McLean and Ngcobo (1995: 184) claimed that isiNgqumo words are primarily based on "deep" isiZulu and suggested that this fact "could be related to the intensely patriarchal nature of Zulu society and the greater need for secrecy". While some scholars have distinguished clearly between certain gay languages as either a "secret language" or a "language of belonging" (Boellstorff 2004: 182), isiNgqumo does not seem to have such a singular role in South African black "gay" society (Rudwick and Ntuli 2008). Although isiNgqumo use seems more prevalent in lower socioeconomic "gay" circles and semiurban township settings, it is not spoken only by skesanas as one particular group of men who engage in same-sex relationships. We argue here that its complex role in the lives of many black men who have sex with men in South Africa and who engage in heterogeneous lifestyles, creates its potential multifaceted functions as a genderlect, an anti-language, a secret code, a language of belonging, and a linguistic means of performing distinct gender and sexual identities (see Msibi 2013, Rudwick and Ntuli 2008, and Rudwick 2010 for examples). Depending on the speaker and the context of use, isiNgqumo does not enjoy a static singular use among speakers. Speakers appeal to any of the above multifaceted functions depending on where they are, the situation they are confronted with, and the people around them.

\section{Hlonipha practice, language use and the connection with isiNgqumo}

The social and linguistic custom of respect (hlonipha) is a cultural pillar of South African Nguni and Sotho societies, and can be understood as a complex behavioural code that requires deferential conduct. Zulu people employ hlonipha, for instance, to show respect towards elders, superiors and ancestors. Hlonipha can manifest itself in multifaceted relations of superordination and subordination, and it is based on complex mechanisms that control language use, posture, gesture, movements, dress code, and other dynamics of a material nature or status.

In "traditional" rural Zulu society, it is primarily married Zulu women" who uphold hlonipha in its strictest sense (Zungu 1985) ${ }^{2}$; in this context, the isiHlonipho language can also be regarded as a genderlect because it expresses a very particular femininity. Here, the variety has been termed "isiHlonipho Sabafazi" (Finlayson 2002) and presents the perceived socially inferior status of females in Zulu society (Herbert 1990). The linguistic aspect of the custom primarily includes the avoidance of certain terms but comprises also, in its traditional form, an entire core lexicon of specific isiHlonipho terms. Although there are many individual and idiosyncratic coinages and lexical inventions of isiHlonipho, there are indeed many stable lexical items that are known by many, especially rural Zulu women

\footnotetext{
${ }^{1}$ We acknowledge, as one reviewer pointed out, that hlonipha is not exclusively used by women, and that it has been used by male sangomas and others as a sign of respect. However, we disagree that women who use isiHlonipho do not have a shared vocabulary as they presumably only use isiHlonipho words individually within their families to show respect to their husbands. To the contrary, as our list of isiNgqumo words attached at the end of this article shows, there are some isiHlonipho words which have been historically shared among married women. Words like "imalasi", "ukubhuluza" and "ukutukela" were, for instance, noted as isiHlonipho words by participants.

${ }^{2}$ For detailed reading on the "traditional" practice of hlonipha among Zulu women, see Raum (1973).
} 
in the province of KwaZulu-Natal (see Rudwick and Shange 2006 for more detail). The social aspect of hlonipha involves the avoidance of any kind of behaviour which might be considered disrespectful. In present-day South African settings, these may include, for instance, showing disagreement to an older or superior person, or speaking in what would be considered an inappropriate manner.

Several scholars (e.g. Hanong Thetela 2002, Rudwick and Shange 2006, Rudwick 2013) have shown how isiHlonipho embodies ambiguities and problems with regard to gender equality that are deeply rooted in African patriarchy. Women who speak isiHlonipho to their husbands and male relatives project a traditional kind of Zulu femininity which can be characterised as submissive. Although these projections and representations may render speakers of isiHlonipho quite vulnerable, the code is endorsed in rural Zulu society due to its cultural rootedness. It is important to stress here that our position is not to assume that Zulu women who use isiHlonipho are oppressed per se - this would be akin to essentialist thinking and would ignore the multiple ways in which gender is contested and negotiated in the daily lives of women, as well as ignoring the evolving nature of Zulu society, including the individual ways in which brides demonstrate respect in their families. However, we suggest that the various ways in which hlonipha cultural and linguistic expectations circulate in wider social engagements may discursively render women's subject positions as inferior to men. We also cannot ignore the fact that there are several lexical items which have evolved through isiHlonipho in the Zulu language, which are shared among speakers.

We argue that both the cultural and linguistic practices of hlonipha also play a crucial part in the power dynamics of some same-sex African relationships in South Africa. Below, we exemplify some terms from the isiHlonipho vocabulary that are employed and sometimes also re-contextualised in isiNgqumo (partly from Msibi 2013):

- umchakisana-boy

- imalasi-dog

- umfazi - a respectable (married) woman/wife; a respected feminine partner in a same-sex relationship

- ukuphumela - to like someone

- ukutukela - to cry

The fact that there is some overlap between isiHlonipho and isiNgqumo ${ }^{3}$ suggests that avoidance and respect may also play an important role in some African male same-sex relationships. While we acknowledge that social performances between heterosexuality and homosexuality, in relation to respect in relationships, may be expected to be generally consistent, it is more the heteronormative, gendered nature in which isiNgqumo and isiHlonipho are used in same-sex relationships which is intriguing. That the language is shared between women who have traditionally been constructed as inferior to men, as well as men who continuously experience discrimination as a result of their perceived femininity, is also relevant, particularly with regard to social power. Youdell (2006) notes that social power rests on social standing, which itself is constituted by a constellation of social identities including class, gender and sexuality. The intersection of lexical items between the two varieties may, however, also be explained by the fact that both linguistic

\footnotetext{
${ }^{3}$ Many more lexical items than the five displayed here belong to an isiHlonipho lexicon and are part of what is considered "deep" isiZulu.
} 
codes are to a large extent based on an archaic form of Zulu, comparable to Shakespearean English, commonly referred to as "deep" Zulu.

Leap (2004: 152) provides an example of isiHlonpiho language use among men in a "gay" newspaper called Exit, where a (male) Zulu writer is proposing marriage to an indoda ('man') which would include the payment of ilobolo ('bridewealth') in order to make $\mathrm{him} /$ her an unkosikazi ('a respectable woman'/ 'feminine man'). He also writes that as a result of this marriage s/he would "ngiyoku hlonipha" ('show respect toward her/his partner'). As Leap (2004: 152) rightly argues, "[b]y proposing to practice hlonipha on the indooda's [sic] behalf, the writer suggests a powerful strategy to asserting the legitimacy of their relationship within Zulu tradition". As can be deduced from the discussion above, the lexical item umfazi is a term capturing respect for one's (feminine) partner in a same-sex relationship, and several participants in our study confirmed that they consider umfazi part of the isiNgqumo lexicon. The use of umfazi implies a certain gendered order which exhibits a "traditional" gender performance because, essentially, an umfazi is only respected because $\mathrm{s} / \mathrm{he}$ is submissive to his/her man. This evidently allows for complex positioning of African men who engage in same-sex relations, and also suggests that they, ironically, draw on heteronormative and heteropoleric categories.

Both hlonipha and ilobolo could be regarded as cultural pillars in Zulu society, and it is not uncommon that Zulu men who engage in same-sex relations would like to endorse either practice. Although same-sex desire and Zulu culture pose a point of contention for many Zulu people, some Zulu men who engage in same-sex relations have found creative ways to reconcile their "gay" lifestyle with Zulu culture. For instance, in 2013 Thoba Sithole and Cameron Modisane, both young males, made international and national headlines when they decided to host South Africa's first traditional African wedding which appealed both to Zulu and Tswana cultures. This same-sex wedding ceremony triggered a storm of criticism from Zulu traditionalists, including the Zulu royal house, for what was perceived as a mockery of Zulu culture. For Thoba and Cameron, however, being "gay" did not go hand-in-hand with a rejection of their African cultures; rather, it necessitated an integration of their "gay" identities within these cultures. Unfortunately, this integration has done little to challenge gender constructions that are based on unequal power relations that have social and linguistic consequences.

\section{Conceptual, theoretical and methodological framework}

Within the field of linguistic anthropology, it has been argued that "one of the greatest weaknesses of previous research on identity [...], is the assumption that identities are attributes of individuals or groups rather than of situations" (Bucholtz and Hall 2004: 376). Importantly for this article, identities are constructed in social actions and the products of particular circumstances, hence, they can always shift and renew themselves from one situation to another and from one time to another. As such, the sexual and gender identities that are produced and performed through language by the participants in this study are highly context-, space- and time-dependent, and vary from one individual to the next, taking into account the idiosyncrasies of the individuals involved, the situation and the subject matter of the communicative act. For instance, the linguistic experience and identity performance of a "gay"-identifying Zulu-speaking man based in deep rural Nkandla will certainly be different to that of a Zulu-speaking man based in the cosmopolitan city of Durban. 
We draw from the work of Youdell $(2000,2005,2006)$ and Butler $(1988,1993)$ to showcase the contested and intersectional nature of identification. Using Butler's work on performativity as well as the feminist theory of intersectionality, Youdell (2005: 6) notes that "categorical names are central to the performative constitution of the subject who is unintelligible, if not unimaginable, without these". Identity categories, she argues, are often (mistakenly) assumed as static and stable. Yet, as Butler (1993) has previously noted, identity is far more fluid, with the "substance view of gender", which sees gender as an expression of "the self", heavily criticised. Identity, in this theoretical positioning, is seen as the historical "stylised repetition of acts" (Butler 1988: 519). This means one has to "dramatise, do and reproduce" culturally sanctioned acts and expectations. These acts are, of course, not perfect as they are dependent on bodily "gestures, movements and enactments"; they are embodied. Successful provisional performance is not due to one's own ability to govern one's actions; rather, it is because current action repeats prior action and "accumulates the force of authority through the repetition or citation of [a] prior, authoritative set of practices" (1993: 18). This historical repetition, according to Butler, is what conditions and limits possibilities for the acts. Gender, therefore, is performatively constituted.

Youdell adds an intersectional perspective to Butler's work to argue that identities operate in constellations. These may reproduce the status quo at the same time as they can open up the potential for change by being reinscribed differently, depending on the context. Although both Youdell and Butler focus on troubling identity categories, we argue that their theorisation can be extended beyond identity categories to include identification processes more broadly. Within this positioning, it becomes no surprise that the skesanas, to be discussed later in this article, perform their sexual and gender identities in the ways they do because their performance of gender and sexual identification is informed by the historical repetition of acts as well as the constellation of their sexual, racial and gender identities, in a national context where patriarchy still strongly dominates.

Language use does not necessarily have to be gendered, but the term "genderlect" has been coined to define a linguistic variety that indexes the gender or sexual identity of a speaker, or expresses different language use among men and women. Although by now widely criticised, the term emerged from previous studies in the Anglo-Saxon context to highlight "women's language" and "men's language", through the compilation of lists presenting lexical and grammatical features of the "languages" (Lakoff 1975) and discussing male-female miscommunication patterns (Tannen 1990). Since the 1990s, sociolinguistic scholars have distanced themselves from such essentialised notions of gender categories, and work with Holmes and Meyerhoff's (2005: 8) avoidance of the idea "that there is a natural basis for separating the social world into two and only two sexes and genders". We employ the term "genderlect" according to Motschenbacher's (2007) theorisation, where "genderlect" means that language "plays a significant role in the performative construction of gender". Accordingly, the term is not used as a simple binary concept but is framed in postmodernist thought where stereotypes of gendered communication can find critical interrogation. From this perspective, the concept of 'genderlect' can also consider "the variable ways people do gender linguistically" (Motschenbacher 2007: 263) and the role "genderlectal stylisation plays in the discursive formation of gendered identities (Motschenbacher 2007: 270).

We draw on semi-ethnographic data and interviews conducted over a period of three years with 26 African (Zulu) males who engage in same-sex relationships in Durban, KwaZulu- 
Natal. Most of these participants were interviewed in bars and other casual spaces, several also in their own homes. During these informal interview sessions, which often lasted several hours, we provided a platform for the interviewee on which he could speak freely about issues he had at heart, but we also prompted certain topics such as the use of isiNgqumo and social, gender and sexual behaviours in relationships. In this article, we also specifically draw on narratives, or cases, from three participants who identify as skesanas, in order to explore the various ways in which gender and sexuality are implicated in linguistic and cultural practices.

\section{Three case studies}

The following three case studies shall illustrate the variable lifestyles of the skesanas we interviewed. The few snippets of conversation, which we mark in italics and inverted commas here, emerged during the fieldwork in informal interviews, and they are selected because they poignantly capture what many other skesana participants have expressed in different words.

Lebo $^{4}$ is a 21-year-old township resident who stays with his mother and two sisters in a small brick house. He identifies as skesana, refers to himself as a "girl", and claims that even his mother has accepted his chosen gender identity the way it is because she only ever speaks about "her girls" when talking to someone about her children. ${ }^{5}$ Lebo does not know his father, but he has a very close relationship with his mother who works as a domestic worker in Durban. Lebo himself earns some money through a part-time waitering job in a small pizzeria; he explains that having more than a part-time job is not feasible for him because he claims to be fully responsible for the household as his one sister is studying and the other is "simply lazy". He repeatedly asserts that he loves running the household and describes cooking, cleaning and "making the place look nice" as his passions. On the weekends, Lebo usually meets his friends who are also mostly skesanas and with whom he likes going to clubs in town. It is in this circle of his friends that he speaks extensive isiNgqumo which, according to his own description, he "loves" and uses eloquently. "We [he and his skesana friends] love to gossip, you know", he proclaims, and describes how they each pick a "straight" man when they go out, talk in isiNgqumo about him during the night and, best-case scenario, lure him into bed towards the end of the night. While Lebo has dated two men over a lengthy period of time, he has never had a stable long-term relationship. He says that, although his mother knows most of his skesana friends, he is not sure how she would react if he brought a boyfriend home. Lebo claims to be entirely happy with his body, with no intentions for a gender reassignment, but he emphasises that he is "definitely the woman" in his relationship with a man. When asked about hlonipha, Lebo asserts that without him showing hlonipha towards his partners, he would not be able to "score": "They [the kind of men he dates] like to be served, you know, so we do everything to please him", he says and giggles.

Sky is a 31-year-old, well-dressed, self-proclaimed skesana who we meet on several occasions in a Durban café. Right at the beginning of the meeting he emphatically proclaims that - although his body may suggest otherwise - "[He is] a full-blown woman". He lives in Umlazi, the largest township in the Durban metropolitan area, where we visit

\footnotetext{
${ }^{4}$ The participants have been given pseudonyms in order ensure their anonymity.

${ }^{5}$ While not dressing overly femininely, Lebo does look like a woman and his face has notably soft features. When meeting the first time, the waiter greeted us by saying "Hello girls" which evidently pleased Lebo a great deal.
} 
him subsequently and where he runs a very small, doubtfully lucrative business making and selling clothes. He says that "style" is very important to him, that his style is feminine and that he does not like dating someone who does not have "style". Speaking isiNgqumo is " $a$ way of life" for Sky. He boasts to be one of the best isiNgqumo speakers in KwaZulu-Natal and would like to compose a dictionary of the linguistic variety some day. He also suggests that isiNgqumo really should be the twelfth official South African language. Sky is currently dating a 46-year-old teacher who, as he phrases it, is " $a$ bit of a big daddy", meaning that he is well-established and supports Lebo financially and emotionally. When at his lover's place, Lebo says he "tries to be a good woman" to his lover - he washes, cooks, cleans and shows him the respect he "deserves as a man". While together, Sky assumes all domestic duties for his lover and emphatically proclaims that he always speaks to him in a respectful manner. After some meetings, Lebo explains to us that he would like to undergo a gender reassignment but, given that his father is still alive, it is an "impossibility", at least for now. Sky explains that it is "an issue of hlonipha" as he is showing respect to his father by not changing his sex.

Blessing is a 23-year-old teacher at a primary school outside of Durban. He recently moved to the city after having lived most of his life in a small town on the south coast of the KwaZulu-Natal province. He currently lives with his partner who is quite masculine and who is also a teacher. During one of the interview sessions, we arrived as Blessing was receiving an instruction from his partner: "Ngicela ungenzele iwashing. Ngyakthuma ${ }^{6}$, ngcela ungenzele iwashingi" ('Please can you wash my clothes [...] I'm asking that you please wash my clothes'). Without any sort of irritation, Blessing started collecting his partner's clothes for washing. For him, this was the role he was meant to perform as a "female" partner. He was the "bottom" in the relationship, "umama wekhaya" ('the woman of the house'), as he puts it. This requires a demonstration of hlonipha ('respect') towards the "man of the house". Blessing feels very constrained by his profession. He is expected to behave, dress and relate to children in his school like a man would. However, he finds this challenging as it limits possibilities for selfexpression: "Well if you are gay, you have to show it. You have to wear tight clothes, you have to be neat and you have to be colourful. You can't just be untidy like all the straight men..." For Blessing, being masculine entails a lack of interest in one's physical appearance, something he believes "straight" men care little about. He is a fluent isiNgqumo speaker, and often uses the language when "ezinye izimeshi ${ }^{7}$ zivakashile" ('when other gay friends visit'). Blessing is also a spiritual man who occasionally goes to church.

These brief descriptions of three skesana individuals are based on the fieldwork of the two authors. Amongst other things, what emerged from this fieldwork is the observation that skesanas who live in the Durban metropolitan area have multiple lifestyles and identities, and perform gender in very distinctive ways; nonetheless, there are significant intersections of similarities. We argue that the overwhelming majority of self-identified skesanas in our sample of interviewees has knowledge of isiNgqumo and consider hlonipha a salient and inescapable aspect of their relationships and, more broadly, of their lives. Many shared knowledge of similar isiNgqumo words, included in the appendix,

\footnotetext{
6 "Ngyakuthuma" does not have an English equivalent. However, "ukuthuma" (lit. 'sending someone somewhere') is often done by someone in authority, giving instruction to a subordinate position to do something. For instance, a parent can direct ("thuma") their children to do some chore. It is often an instruction given by a "dominant" person to a "subordinate" for some task to be done.

7 This is a colloquial term for overly effeminate "gay" men, and has a similar meaning to skesana.
} 
some of which they claimed emerged from hlonipha.

\section{Constructing a skesana identity}

It was previously suggested that, in particular, African "gay" men who identify as skesanas make use of isiNgqumo (Rudwick and Ntuli 2008, Ntuli 2009) and that it is they who identify most strongly with the linguistic variety. The etymology of the term and the origin of the social construct assumedly have their roots in the early- and mid- $19^{\text {th }}$ century mine environments. South African mines were based on the migrant labour market, and mineworkers were away from their wives and families in a predominantly maledominated environment for many months of the year. Ntuli (2009: 68) also traces the etymology of the term skesana to the mining environment. He writes that "if a gay boy or man [at the mines] called himself a skesana it meant that he was the wife or the submissive lover in the relationship and he should be with the other skesanas in their section of the sheebeen ${ }^{8}$ [sic]". In their seminal piece, Moodie, Ndatshe and Sibuyi (1988) describe same-sex acts in the South African mines as heteronormative in the sense that the "boy-wives" or izinkotshane 9 of otherwise "straight" mineworkers took on the social and sexual roles assumed by women in a heterosexual relationship, with others even expected to dress in women's attire to please their "husbands" (Murray 2000, Epprecht 2013). Similarly, Gunkel (2010: 95) suggests that miners who engaged in same-sex relationships could maintain their heterosexual identity by considering skesanas and izinkotshane as women rather than men. Although in the post-apartheid state "gay" life offers alternatives to "traditional" and dominant femininities and masculinities, South Africans in same-sex relationships often do not challenge these hegemonic structures (Potgieter 2006).

While it is generally not uncommon for South African black men who desire same-sex engagements to be intimate with men whom they consider to be "straight", the case of the skesanas (and other similar identifications) has its roots in a thoroughly heteronormative "Weltanschauung" ('worldview'). McLean and Ngcobo (1995: 166) aptly quote one of their informants, saying "My male lover is not gay, he is just heterosexual. I am always the woman in a relationship". Several of our interviews echoed similar statements. When skesanas make use of the adjective "straight" in reference to their partners, this not only encapsulates sexual behaviour but also appearances that are stereotypically masculine, and a behaviour carrying with it the notion of being tough and masculine (Reddy and Louw 2002). To have sex with men such as these represents a significant conquest for some skesanas. Importantly, African men who engage in samesex relations and identify as skesana rarely date each other or are sexually intimate with each other, and in such a rare case, the act is not considered "sex", even if it results in orgasm (McLean and Ngcobo 1995).

Our fieldwork suggests that men who identify as skesana often form close friendships to

\footnotetext{
8 "Shebeen" is the colloquial term for unlicensed bars in South African townships.

${ }^{9}$ Izinkotshane were often younger male miners who were lured by financial gifts and other luxuries to "marry" older men. The older men would in turn receive sexual favours, mostly through ukuhlobonga ('thigh sex'), with the younger men not allowed to reciprocate. Additionally, it was expected that the young men would perform "wifely" duties such as "adopting feminine attire, wearing false breasts fashioned from coconuts, putting on scent, keeping their faces well-shaven, and even sipping wine or other sweet liquors (as opposed to the "husbands" manly swilling of beer)" (Epprecht 2013: 61). Although izinkotshane and skesanas differed in that the former often identified themselves as heterosexual while the latter saw themselves as women, both identities provided sexual services in the mines and both took on "female" roles which subscribed to heteronormativity in the relationships in which they engaged.
} 
the extent that they may "love" each other on a platonic level ${ }^{10}$, but because many of them think of themselves as women, they would not be with another skesana as this would be tantamount to a lesbian relationship. Due to their rigid heteronormative perspectives, many skesanas also find lesbians "strange" because they are with a person who has the same gender identity. What is crucial is that all the interviewees who explicitly identified as skesana viewed their femininity as "naturally given" and thought it to be "un-natural" that two "men-men" would have sex or an intimate relationship with each other. Skesanas, due to their "traditional" Zulu femininity, show submissiveness through hlonipha to their male partners, just as women generally do in "traditional" African heterosexual relationships. It has been argued that skesanas, as the "female" partners, "may be subject to the demands of their partners", just as women generally are in many heterosexual relationships (Reddy and Louw 2002: 91). This is clearly evident in the narratives presented. It is this unequal power relation which often also lends skesanas to show hlonipha towards their partners to a much greater extent than the partners show hlonipha towards them. In many cases, this includes serving their partners on the domestic level and expressing gender performances of a very particular and "traditionally" feminine kind.

The identity as a skesana is by no means fixed; rather, as has been noted in several works, such identities may take on particular localised and idiosyncratic meanings. For instance, Reid $(2006,2013)$ has shown how "gay" identities can emerge and be practised in other South African contexts. In How to become a 'real gay': Identity and terminology in Ermelo, Mpumalanga, Reid introduces the reader to "ladies", Ermelo's skesana equivalents. These are feminine men who maintain female social and sexual roles, and ideally get sexually involved with "gents" - "straight men known or suspected of being available as sexual partners to homosexual men" (2006: 139) - and injongas ("[men who are] attracted to and involved with other men, but who [maintain] a male social and sexual role in a same-sex relationship" (Reid 2006: 139)). The "ladies" often use "jolly-talk", a "gay" linguistic variety equivalent to isiNgqumo, to communicate. For "ladies", sexual acts cannot be with other "ladies" as this becomes "lesbian sex". These men see their sexual identifications as closely intertwined with their gender identities; they perceive themselves as women and expect to be treated like women in their relationships with other men.

There may also be some parallels in the construction of skesana identities and the Israeli oxtša $a^{11}$, the latter who are described by Levon (2012: 189; italics our emphasis) as "young, effeminate gay men [...], who are physically slight, wear makeup and the latest designer clothing, and are obligatorily passive during sex". Importantly, however, in Levon's (2012) study it is argued that most gay men in Israel are not using Oxtšit as a means to express an alternative $o x t \check{s} a$ identity but rather that they just make use of random Oxtšit words in conversation without self-identifying as an oxtša. This stands in stark contrast to our study. The participants in our study openly identify as skesana and isiNgqumo is an important aspect of the "gay" sub-group of skesanas examined here.

\footnotetext{
${ }^{10}$ Reid's (2006) work confirms this finding through his discussion of the "ladies" (skesana equivalents) in Ermelo in the province of Mpumalanga. Reid notes that the idea that two "ladies" could be together in a relationship was met with "thigh-slapping hilarity" by his participants, as this would constitute "lesbianism". One of the participants stated the following in response to the question as to whether s/he could be in a relationship with his/her friend who was also a lady: "I love him very much, but I am not a lesbian!"(Reid 2006: 139).

${ }^{11}$ We also acknowledge similarities to travesti in Brazil (Kulick 1998) and yan daudu in Nigeria (Gaudio 2008).
} 
This is not to say that all isiNgqumo-speakers are skesanas or that all skesanas speak isiNgqumo, but it is safe to argue that South African "gay" men who identify as skesana know and speak, to some degree, the linguistic variety. While the ability to speak isiNgqumo is not the sole marker of a skesana identity, it is still a salient one. The vocabulary of isiNgqumo may also be far more extensive than other gay varieties examined in the literature. In fact, one of our interviewees claimed that isiNgqumo has "well over 1000 words", while others described it as a "full-blown" language, and still others demanded that it receive the status of the twelfth official South African language (see also Rudwick and Ntuli 2008) ${ }^{12}$.

\section{Conclusion}

While this article does not represent an exhaustive account of the connections between isiNgqumo and isiHlonipho as genderlects, we have illustrated how heteronormativity finds expression in the ways in which some men desiring other men perform their sexualities, as well as the role of language in such expressions. We also hope this initial exposition will generate further research that exposes the Zulu cultural embeddedness of isiHlonipho on isiNgqumo linguistic practices, thus offering greater insight into these issues. Finally, it is important to understand how processes of identification are trapped in processes of power. Through understanding identification as intersectional and non-static, we begin to see ways in which historical acts find reinscription in current performances of identification, and are thus able to trouble heteronormativity in more meaningful ways.

From our research study, it is clear that isiNgqumo linguistic practices among the skesana men interviewed are highly gendered, with hlonipha playing quite a major role in the ways in which the men perceive themselves, how they relate to their partners, and how they perform gender in general. At a cursory glance, the fluidity represented by the skesana identities, in terms of debunking the gender category, is quite profound, not least due to what appears to be an evolved understanding of gender from these men. However, deeper scrutiny of their gender and sexual identification performances suggests a troubling irony: these men construct their identifications along very fixed gender binary lines (male/female) informed by heteronormativity. This not only highlights the dominance of patriarchy in a transformed, "equal" post-apartheid South Africa, but also highlights the extent to which fixed binary systems inform gender practices.

\section{References}

Baker, P. 2002. Polari: The lost language of gay men. London/New York: Routledge.

Boellstorff, T. 2004. 'Authentic, of course': Gay language in Indonesia and cultures of belonging. In W.L. Leap and T. Boellstorff (Eds.) Speaking in queer tongues. Urbana/Chicago: University of Illinois. pp. 181-201.

Bucholtz, M. and K. Hall. 2004. Language and identity. In A. Duranti (Ed.) A companion to linguistic anthropology. Malden and Oxford: Blackwell Publishing. pp. 369-394.

Butler, J. 1993. Critically queer. GLQ: A Journal of Lesbian and Gay Studies 1(1): 17-32.

\footnotetext{
${ }^{12}$ South Africa has 11 official languages, namely Zulu, Xhosa, Sotho, Northern Sotho, Tswana, Swati, Ndebele, Venda, English, Afrikaans and Tsonga.
} 
Butler, J. 1988. Performative acts and gender constitution: An essay in phenomenology and feminist theory. Theatre Journal 40(4): 519-531.

Cage, K. 2003. Gayle: The language of kinks and queens: A history and dictionary of gay language in South Africa. Johannesburg: Jacana Press.

Epprecht, M. 2013. Hungochani: A history of dissident sexuality is southern Africa $\left(2^{\text {nd }}\right.$ edition). Montreal: McGill-Queen's University Press.

Finlayson, R. 2002. Women's language of respect: 'Isihlonipho sabafazi'. In R. Mesthrie (Ed.) Language in South Africa. Cambridge: Cambridge University Press. pp. 279-296.

Gaudio, R. 2008. Out on video: Gender, language and new public spheres in Islamic northern Nigeria. In B.S. McElhinny (Ed.) Words, worlds, and material girls: Language, gender, globalization. Berlin: Mouton de Gruyter. pp. 237-286.

Gunkel, H. 2010. The cultural politics of female sexuality in South Africa. New York: Routledge.

Hanong Thetela, P. 2002. Sex discourses and gender constructions in Southern Sotho: a case study of police interviews of rape/sexual assault victims. South African Linguistics and Applied Language Studies 20(3): 177-189.

Herbert, R. 1990. 'Hlonipha' and the ambiguous woman. Anthropos 85: 455-473.

Holmes, J and M. Meyerhoff. 2005. Different voices, different views: An introduction to current research on language and gender. In J. Holmes and M. Meyerhoff (Eds.) The handbook of language and gender. Oxford: Blackwell. pp. 1-18.

Kulick, D. 1998. Fe/male trouble: The unsettling place of lesbians in the self-images of Brazilian travesti prostitutes. Sexualities 1(3): 299-312.

Lakoff, R. 1975. Language and woman's place. New York: Harper \& Row.

Leap, W.L. 2004. Language, belonging and (homo)sexual citizenship in Cape Town, South Africa. In W.L. Leap and T. Boellstorff (Eds.) Speaking in queer tongues: Globalization and gay language. Illinois: University of Illinois Press. pp. 134-162.

Levon, E. 2012. The voice of others: Identity, alterity and gender normativity among gay men in Israel. Language in Society 41: 178-211.

McLean, H. and L. Ngcobo. 1995. 'Abangibhamayo bathi ngimnandi' (Those who fuck me say I'm tasty): Gay sexuality in Reef townships. In M. Gevisser and E. Cameron (Eds.) Defiant desire: Gay and lesbian lives in South Africa. New York/London: Routledge. pp. 158-185.

Moodie T.D., V. Ndatshe and B. Sibuyi. 1988. Migracy and male sexuality in the South African gold mines. Journal of South African Studies 14(2): 228-256. 
Motschenbacher, H. 2007. Can the term 'genderlect' be saved? A postmodernist redefinition. Gender and Language 1(2): 255-278.

Msibi, T. 2013. Homophobic language and linguistic resistance in KwaZulu-Natal, South Africa. In L.L Atanga, S.E. Ellece, L. Litosseliti and J. Sunderland (Eds.) Gender and language in sub-Saharan Africa. Amsterdam/Philadelphia: John Benjamins. pp. 253-274.

Murray, S.O. 2000. Homosexualities. Chicago: University of Chicago Press.

Ntuli, N. 2009. IsiNgqumo: Exploring Origins, Growth and Sociolinguistics of an Nguni Urban-Township Homosexual Sub-Culture. Unpublished MA thesis, University of KwaZulu-Natal.

Potgieter, C. 2006. Masculine bodies, feminine symbols: Challenging gendered identities or compulsory femininity. Agenda 20(67): 116-127.

Raum, O.F. 1973. The social functions of avoidances and taboos among the Zulu. Berlin: Mouton de Gruyter.

Reddy, V. and R. Louw. 2002. Black and gay: Perceptions and interventions around HIV in Durban. Agenda 17(53): 89-95.

Reid, G. 2006. How to become a 'real gay': Identity and terminology in Ermelo, Mpumalanga. Agenda 20(67): 137-145.

Reid, G. 2013. How to be a real gay: Gay identities in small-town South Africa. Pietermaritzburg: UKZN Press.

Rudwick, S. 2011. Defying a myth: A gay sub-culture in contemporary South Africa. Nordic Journal of African Studies 20(2): 90-111.

Rudwick, S. 2013. Gendered linguistic choices among isiZulu-speaking women in contemporary South Africa. In L.L Atanga, S.E. Ellece, L. Litosseliti and J. Sunderland (Eds.) Gender and language in sub-Saharan Africa. Amsterdam/Philadelphia: John Benjamins. pp. 233-251.

Rudwick, S. and N. Ntuli. 2008. IsiNgqumo: Introducing a gay Black South African linguistic variety. Linguistics and Applied Language Studies 26(4): 445-456.

Rudwick, S. and M. Shange. 2006. Sociolinguistic oppression or expression of 'Zuluness'? 'IsiHlonipho' among isiZulu-speaking females. South African Linguistics and Applied Language Studies 24(4): 473-482.

Sigamoney, V. and M. Epprecht. 2013. Meanings of homosexuality, same-sex sexuality, and African-ness in two South African townships: An evidence-based approach for rethinking same-sex prejudice. African Studies Review 56(2): 83-107.

Tannen, D. 1990. You just don't understand: Women and men in conversation. London: Virago. 
Youdell, D.C. 2000. Schooling Identities: An Ethnography of the Constitution of Pupil Identities. Unpublished $\mathrm{PhD}$ thesis. University of London.

Youdell, D.C. 2005. Sex-gender-sexuality: How sex, gender and sexuality constellations are constituted in secondary schools. Gender and Education 17(3): 249-270.

Youdell, D.C. 2006. Impossible bodies, impossible selves: Exclusions and student subjectivities. Dordrecht: Springer.

Zungu, P.J. 1985. A study of Hlonipha terms amongst Zulu. Essay submitted to the Department of Zulu, University of Natal, Durban.

\section{Appendix: List of isiNgqumo words}

1. abajuketi - students

2. affair - the township "gay" word for "relationship"

3. amafezela - straight men

4. amaqaphelo - eyes

5. ayine - fuck

6. bhadlaza - to buy

7. gweni-darling

8. imalasi - dog

9. imbakhla - Indian person

10. imbhamo - food

11. imbube - those who switch between playing penetrative and receptive roles in homosexual sex; a certain type of traditional music

12. imfazo - war

13. imju/inju - father

14. injonga - those who play the active, penetrative (butch or top) role in homosexual sex

15. iqenge - boyfriend

16. isichibi - beer

17. isichibi/inketshezi - drink about to be finished

18. isidudula - fat person; car

19. isifico-medicine

20. isigeqo - a drink

21. isitabane-hermaphrodite; someone who is gay

22. isitende - a home

23. izimbovu - women

24. izimvakazi - clothes

25. kehlo - a marriage ceremony between men in migrant labour hostels

26. mandlwana - "housie-housie"

27. mantshingelane - guard

28. morabaraba - a boardgame similar to draughts and played with bottle tops

29. mthetho - the set of rules governing relationships between men in migrant labour hostels

30. Nozitshwaxa-God

31. obhabsi basethi - the sandwiches are here

32. obhovu - girl

33. opheni - money (comes from Eng. penny)

34. panga-a homemade township axe 
35. pantsulas - a macho township guy

36. portfolio - one's assigned role as either a skesana or an injonga

37. Regina Mundi-Sowetho's principle cathedral famous for anti-apartheid gatherings in the $1980 \mathrm{~s}$

38. shaya ndlwabu - to masturbate

39. skesana - men who construct themselves as feminine and who mainly play a receptive role in same-sex sexual engagements

40. ubukhwashu - black person

41. udayi-white person

42. ukubhama - to have sex

43. ukubhedlela - to sleep

44. ukubhuluza - to give birth

45. ukucoshela - to listen

46. ukufaza - to bitch

47. ukufoza - to smoke

48. ukugaya - to drink alcohol

49. ukugeqa-drink

50. ukujuketisa - to teach

51. ukukala - to look

52. ukuluthula - to kiss

53. ukuphumela - to like someone

54. ukushaya emqhumeni - to go to work

55. ukushaya/ukuguza - to go/walk

56. ukutukela - to cry

57. ukuwindi - to desire (someone)

58. ukuzinza - to stay

59. umahotelana - hot spirits/drinks

60. umambhu - mother/old woman

61. umbhamo - food

62. umchasikana-boy

63. umfundisi-elder

64. umjuketisi/abajuketisi - teacher/teachers

65. umngeni-water

66. umqhumo - work

67. umqingo - phone

68. umvelo - beautiful (nature originally)

69. ushwili - a boy too young for a person to be in a relationship with

70. uvele/ubonakele - pretty individual 